\title{
Creation and analysis of a GIS land-use map for the end of the Edo period in Tokyo
}

\author{
Takeshi Noma $^{\text {a }}$ \\ ${ }^{a}$ Tokyo Metropolitan University nomatake141421356@yahoo.co.jp
}

Keywords: land-use, Edo period, GIS

\begin{abstract}
:
The Meiji Restoration marks its 150th anniversary in 2018. This historical event memorializes the transition between the Tokugawa shogunate system and the Meiji government, a turning point in the modernization of Tokyo. In such an anniversary year, it is important to look back on the history of Tokyo, a city of global significance.
\end{abstract}

Urban development in Tokyo has been commented on from various perspectives by Jinnai (1992), Maki (1980), Okamoto (2017), and others. However, few studies have followed quantitative changes to the city using GIS. In this study, a landuse map of Tokyo at the end of the Edo period was made as a GIS date. Using this map, we analyzed how land was used in the city during the Edo period; in the future we will quantitatively analyze land-use change up to the present.

To create land-use maps, we first projected a paper map, the "restored Edo information map (geometrically corrected)," onto ArcGIS, and overlaid a 20-m mesh on top of it. Then, by manually inputting the attributes of each mesh, the map of Figure 1 was completed.

Figure 2 shows the percentage of each land use based on the created land-use map. While more than $60 \%$ of the area comprised samurai residences, $14 \%$ was occupied by townspeople, even though townspeople accounted for more than half of the population. In addition, correlation with topographical data created using "the Digital Map 25000 (Land Condition)" shows the following. The upper-class samurai lived in comfort on the plateaus, while lower-class townspeople typically lived in the lowlands. The samurai used the sloping land of the plateau in characteristic ways. They built mansions at its edge, creating gardens that utilized springs flowing from the cliffs. In many cases, temples or shrines were located at one end of the valley so that these religious structures served as the boundary between the samurai and the townspeople.

As has been noted, land use in the Edo period was characterized by a profusion of samurai residences. Additionally, land was used differently depending on topography. These results were quantitatively and comprehensively reached using GIS. Further, by using the same method to create land-use maps after the Meiji Restoration, we see that land-use change can be followed mechanically on GIS. 


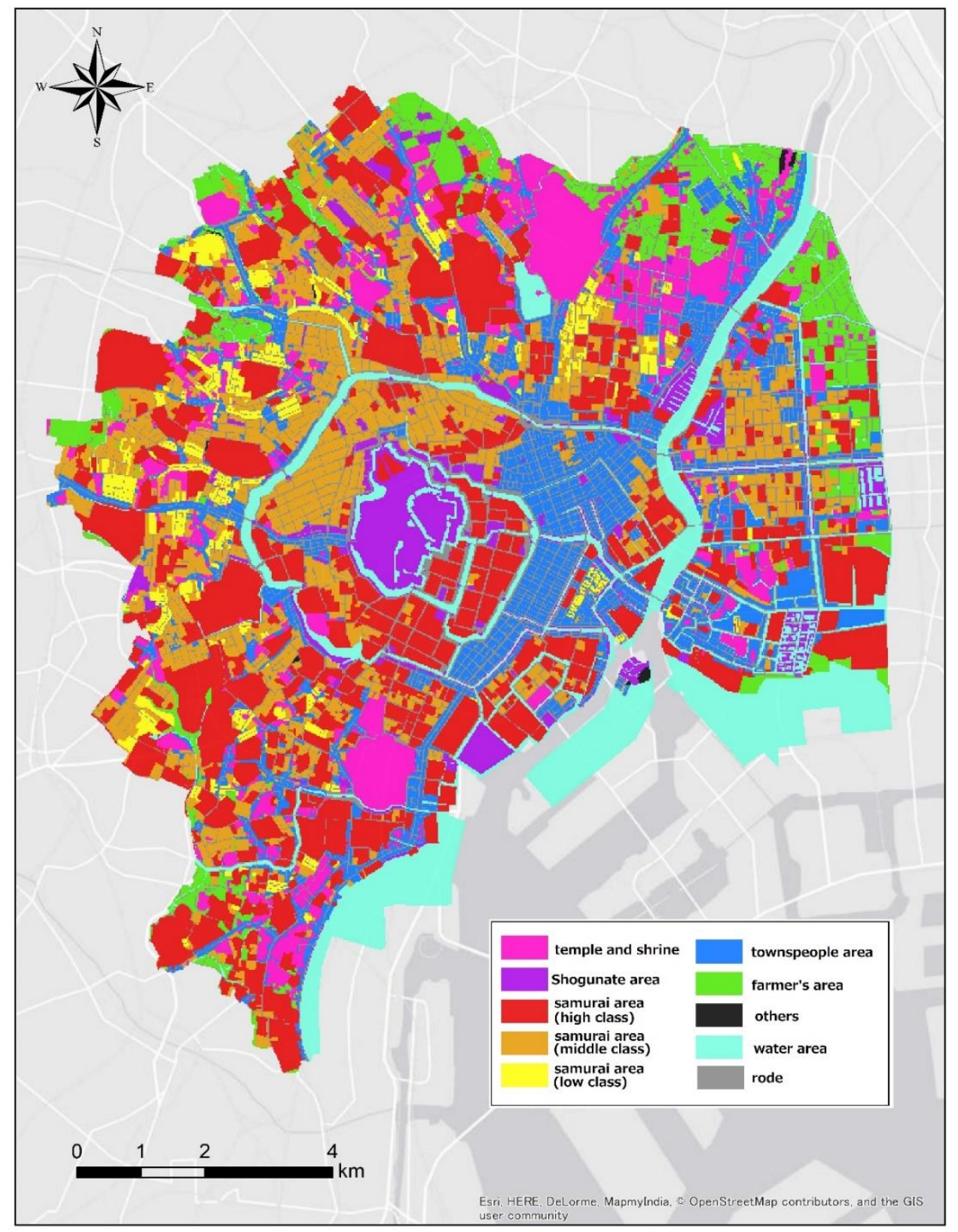

Figure 1. Land-use map at the end of Edo period

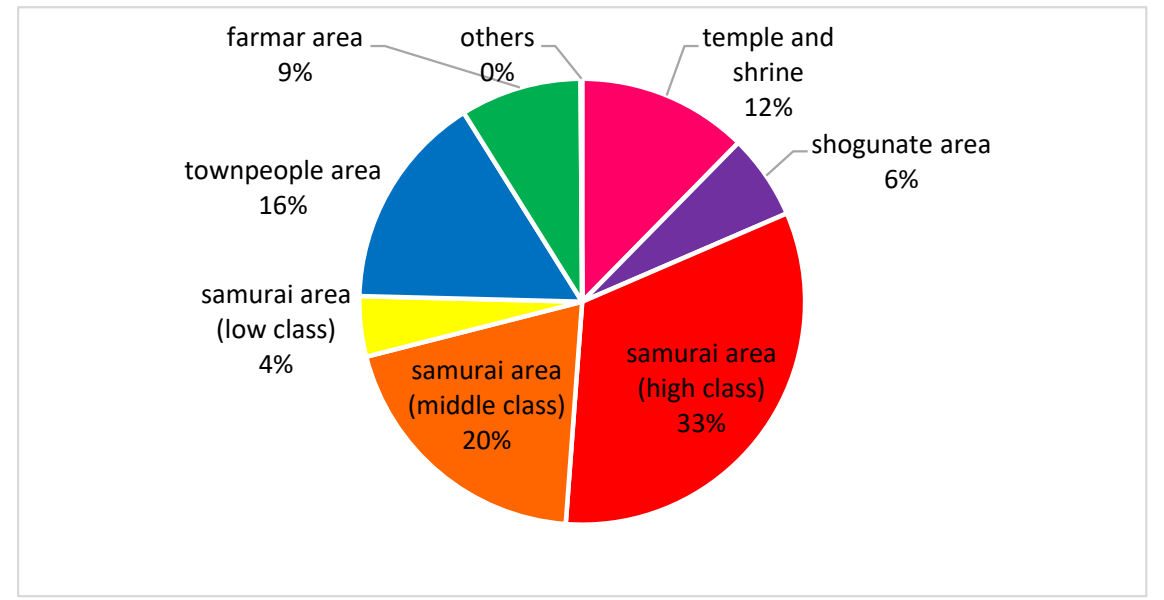

Figure 2. Percentage of land use 